\title{
Are lower rates of surgery amongst older women with breast cancer in the UK explained by co-morbidity?
}

\author{
K Lavelle ${ }^{*, 1}$, A Downing ${ }^{2}$, J Thomas ${ }^{3}$, G Lawrence ${ }^{4}$, D Forman ${ }^{2,3,6}$ and SE Oliver ${ }^{3,5}$ \\ 'School of Nursing, Midwifery and Social Work, The University of Manchester, 5.332 Jean McFarlane Building, Oxford Road, Manchester M I 3 9PL, UK; \\ ${ }^{2}$ Centre for Epidemiology and Biostatistics, University of Leeds, Leeds LS2 9JT, UK; ${ }^{3}$ Northern and Yorkshire Cancer Registry and Information Service, \\ Level 6, Bexley Wing, St James's University Hospital, Beckett Street, Leeds LS9 7TF, UK; ${ }^{4}$ West Midlands Cancer Intelligence Unit, Public Health Building, \\ The University of Birmingham, Birmingham B $52 \pi$, UK; ${ }^{5}$ Department of Health Sciences, University of York and the Hull York Medical School, Seebohm \\ Rowntree Building, Heslington YOIO 5DD, UK
}

BACKGROUND: Around $60 \%$ of women $\geqslant 80$ years old, in the UK do not have surgery for their breast cancer (vs $<10 \%$ of younger age groups). The extent to which this difference can be accounted for by co-morbidity has not been established.

METHODS: A Cancer Registry/Hospital Episode Statistics-linked data set identified women aged $\geqslant 65$ years diagnosed with invasive breast cancer (between I April 1997 and 3I March 2005) in two regions of the UK $(n=23038)$. Receipt of surgery by age was investigated using logistic regression, adjusting for co-morbidity and other patient, tumour and treatment factors.

RESULTS: Overall, $72 \%$ of older women received surgery, varying from $86 \%$ of $65-69-$ year olds to $34 \%$ of women aged $\geqslant 85$ years. The proportion receiving surgery fell with increasing co-morbidity (Charlson score $0=73 \%$, score $1=66 \%$, score $2+=49 \%$ ). However, after adjustment for co-morbidity, older age still predicts lack of surgery. Compared with 65-69-year olds, the odds of surgery decreased from 0.74 (95\% Cl: 0.66-0.83) for 70-74-year olds to 0.13 (95\% Cl: 0.1 I-0.14) for women aged $\geqslant 85$ years. CONCLUSION: Although co-morbidity is associated with a reduced likelihood of surgery, it does not explain the shortfall in surgery amongst older women in the UK. Routine data on co-morbidity enables fairer comparison of treatment across population groups but needs to be more complete.

British Journal of Cancer (2012) I07, |175-||80. doi:I0.1038/bjc.2012.192 www.bjcancer.com

Published online 9 August 2012

(c) 2012 Cancer Research UK

Keywords: co-morbidity; breast cancer; older; surgery

Older women experience the highest incidence and worst survival for breast cancer in England (Cancer Research UK, 2009; Office for National Statistics, 2010). The relative 5-year survival for women diagnosed with breast cancer in England between 2001 and 2006 falls from $90 \%$ for $50-59$-year olds to $69 \%$ for women aged $\geqslant 80$ years old; a drop in survival of a scale not seen in comparable countries (Cancer Research UK, 2009; Coleman et al, 2011). Similar patterns by age have also been seen for cause-specific survival in the UK (Ali et al, 2011). It has been suggested that improved management of older cancer patients has a key role in improving overall cancer survival in England, and for age-based access to treatment to be investigated as a priority (Foot and Harrison, 2011).

Studies from the UK, North America and Europe demonstrate substantial differences in the management of older women with breast cancer (Bouchardy et al, 2007; Louwman et al, 2007; Lawrence et al, 2011). Care of older women is less likely to be in accordance with treatment guidelines. They are less likely to receive primary surgery, radiotherapy following breast conserving

*Correspondence: Dr K Lavelle;

E-mail: katrina.j.lavelle@manchester.ac.uk

${ }^{6}$ Current address: The International Agency for Research on Cancer, I50, cours Albert Thomas, F-69372 Lyon Cedex 08, France

Received 3 February 2012; revised 12 April 2012; accepted 14 April 2012; published online 9 August 2012 surgery or chemotherapy (Wyld et al, 2004; Giordano et al, 2005; Naeim et al, 2006; Lavelle et al, 2007b). Lack of surgical management appears to be a particular problem for older breast cancer patients in the UK, only $39 \%$ of women aged $\geqslant 80$ years presenting with symptomatic breast cancer in 2007 had surgery compared with $90 \%$ of those aged under 50 years (Lawrence et al, 2011). Similar patterns have been demonstrated in previous UK studies (Wyld et al, 2004; Lavelle et al, 2007a, b).

Treatment guidelines for early-stage breast cancer are largely based on trials, which under-represented older women (Scottish Intercollegiate Guidelines Network, 2005; Association of Breast Surgery at BASO, 2009; National Institute for Clinical Excellence, 2009) and there has been debate about the extent to which their results can be applied to older patients (Balducci et al, 2001; Ring et al, 2011). However, the current policy on treatment of cancer for the elderly in the UK is given in the Cancer Reform Strategy (CRS) (Department of Health, 2007). While acknowledging the importance of ongoing trials, it states that patient health and patient choice are the only acceptable reasons for older breast cancer patients not receiving clinically appropriate treatment. This approach is supported in management of breast cancer by a systematic review comparing surgery plus endocrine therapy with endocrine alone in women aged $\geqslant 70$ years, which reported poorer progression-free survival without surgery. The authors concluded surgery should only be omitted in women with oestrogen receptor-positive tumours who are 'unfit for, or refuse, surgery' (Hind et al, 2007). 
One measure of patient health/fitness is co-morbidity (i.e., pre-existing illness in addition to the primary diagnosis). Co-morbidity can be measured in several ways, including scoring individual patients' health records or using information extracted from administrative databases, for example, the Charlson Index (Charlson et al, 1987), or Index of Co-existing Diseases (Imamura et al, 1997). The value of routine adjustment for co-morbidity applicable to large data sets has been emphasised in facilitating fairer interpretation of practice across the patient groups (National Cancer Intelligence Network, 2010).

Despite the recognised importance of adjustment for co-morbidity, previous UK studies which do this, for older breast cancer patients, are limited to a small prospective cohort study $(n=76)$, which scored co-morbidity directly from case notes of women aged $\geqslant 65$ years with early-stage breast cancer. The authors found the odds of women aged $\geqslant 80$ years not having surgery for operable (stage I-IIIa) disease were 44 times that of women aged 65-79 years, even when adjusted for comorbidity (Lavelle et al, 2007a).

Larger-scale studies have been undertaken in the United States, using diagnostic data held on administrative databases. All demonstrate that older age continues to predict not having surgery even when co-morbidity is adjusted for (Hillner et al, 1996; Giordano et al, 2005). The generalisability of these results to the UK, is limited by differences between the health care systems and survival rates (Coleman et al, 2008).

Recent developments in data linkage in England between cancer registration and hospital in-patient admission data (the Hospital Episode Statistics, HES) (Health and Social Care Information Centre, 2009) provides a new opportunity to develop and adjust for routine measure of co-morbidity. This study focuses on the treatment of breast cancer in women, aged $\geqslant 65$ years, using cancer registry data linked to HES to investigate disparities in primary surgery by age and whether adjustment for co-morbidity, can explain any differences found.

\section{METHODS}

Analyses were based on a data set of all registrations with invasive breast cancer (ICD C50) in females aged $\geqslant 65$ years in two English cancer registries serving the Northern and Yorkshire (region 1, catchment population $6.6 \mathrm{M}$ ) and West Midlands (region 2, catchment 5.3 M) between 01 April 1997 and 31 March 2005 $(n=29336)$. These were matched to an extract of HES available to English cancer registries, which include records of all individuals with at least one instance of a recorded diagnosis of cancer. Matching was based on all or combinations of: unique NHS number, date of birth and postcode at diagnosis. Patients treated in hospitals outside the two regions, or in private hospitals, were excluded. This resulted in a data set of 23038 women (79\% of all registrations in this age range) in which co-morbidity could be assessed. Surgical treatment was identified from standard procedure codes for mastectomy (OPCS B271-275, B278-279) and breast-conserving surgery (BCS) (B281-283, B288-289). Women were classified as receiving primary surgery if they had mastectomy or BCS recorded within 6 months of diagnosis or had these treatments recorded but the date of treatment was not known, or had a record of having received these treatments in the cancer registration data.

A Charlson co-morbidity score was calculated for each individual based on the diagnostic codes (excluding cancer) recorded from Hospital Episode Statistic in hospital admissions in the year before diagnosis (Charlson et al, 1987). The cancer component (i.e., pre-existing cancer) of the score was drawn from cancer registry data. For this study population, the Charlson scores ranged from 0 (no co-morbidities) to 7 (severe co-morbidity) and were grouped for analysis.

Patient age, stage of disease (using a modified version of the TNM system (UICC, 2002) with stage categorised as I, II, III, IV or missing), tumour grade (well, moderate, poorly differentiated or missing) (Bloom and Richardson, 1957), period of diagnosis (1997-99, 2000-02 or 2003-05) and region were obtained from the cancer registry data. An area-based measure of socioeconomic background, the 2004 Index of Multiple Deprivation Income Domain (Office of the Deputy Prime Minister, 2005) was derived from the postcode at diagnosis. Self-reported ethnicity was derived from HES data (categorised as White, non-White).

All explanatory variables were investigated in univariable analysis using Pearson's $\chi^{2}$ test, $\chi^{2}$ test for trend and univariable logistic regression analyses to generate odds ratios (ORs) (twotailed with $\alpha=0.05)$. Those that were significantly associated with the outcome (primary surgery) were included in an initial multivariable regression analysis from which variables where excluded on the following basis; (1) no significant effect or (2) significant effect only in the 'missing' category of data. The covariates included in the final model were age (as a categorical variable), co-morbidity score $(0,1,2+)$, stage, region and period of diagnosis. The results are presented as ORs with $95 \%$ confidence intervals (CIs). Sensitivity analyses were conducted on data sets restricted to individuals with early-stage disease (I and II), and excluding the most elderly patients ( $\geqslant 85$ years).

The development of the data set used in this study was approved by the Department of Health Patient Information and Advisory Group (PIAG 2-05(f)/2007). Ethical approval was received by the Department of Health Sciences Research Governance Board (University of York 11 February 2009).

\section{RESULTS}

In total, 23038 of the 29336 (79\%) cancer registrations for invasive breast cancer had a matching HES record and hence a potential measure of co-morbidity. The proportion of registrations with matching HES records varied with age, with lower levels in the most elderly $\quad(65-69=87 \%, \quad 70-74=86 \%, \quad 75-79=82 \%$, $80-84=73 \%, \geqslant 85=58 \%$ ). Reasons for non-linkage include a missing NHS number, or the patient's cancer being recorded on the registry by Death Certification Only (DCO). In the case of a DCO it would be unlikely for the patient to be included in the HES data extract, which was conditional on a recorded cancer diagnosis at some point. The proportion of registrations missing an NHS number was small $(<2 \%)$ and did not change significantly with age. However, the DCO rate did change with a higher level for those aged $\geqslant 85$ years $(65-69=0.6 \%, 70-74=1.0 \%, 75-79=1.7 \%$, $80-84=2.7 \%$, $\geqslant 85=7.6 \%)$.

The overall characteristics of the group are described in Table 1. Approximately, $50 \%$ of the women were aged $65-74$ years, $38 \%$ $75-84$ years, and $12 \%$ over 85 years. Nearly two thirds of the sample $(65.4 \%)$ were recorded with early-stage disease (I or II) at diagnosis, $8.6 \%$ were stage III and $6.1 \%$ presented with metastatic (stage IV) disease. For $19.9 \%$ no stage was recorded. Regarding comorbidity, $85.7 \%$ had no co-morbid conditions identified in diagnostic codes of in-patient admissions, $10.0 \%$ had a Charlson score of 1 and $4.3 \%$ scored 2 or more. Co-morbidity scores increased with age with the proportion with Charlson score $\geqslant 1$ being $11.5 \%$ amongst $65-69$-year olds and $19.6 \%$ for women aged $85+$ (Figure 1). Co-morbidity was also greater in those living in more deprived areas (score $\geqslant 1$ : least-deprived quintile $=11.2 \%$; 2nd quintile $=11.2 \%$; 3 rd quintile $=14.1 \%$; 4 th quintile $=15.2 \%$; most deprived quintile $=18.0 \% P($ trend $)<0.001)$ and increased across time (score $\geqslant 1: \quad 1997-99=11.0 \% ; \quad 2000-02=14.0 \%$; $2003-05=18.7 \% P($ trend $)<0.001)$.

Overall, $71.6 \%$ received primary surgery. The proportion of women receiving surgery decreased substantially with older age (Table 2). Just over $86 \%$ of $65-69$-year olds had surgery compared with around a third of women aged $\geqslant 85$ years. Of those with no recorded co-morbidities, $73.4 \%$ underwent surgery, compared with 
$\underset{\text { OPEN }}{B J} \mathrm{O}$

$66.2 \%$ of those with a score of 1 and $49.1 \%$ of those with a score of $2+$. Across all age groups a smaller proportion of the patients with co-morbidity (score of $1+$ ) had surgery compared with those with no co-morbidity (Figure 2). However, the difference in surgical rates was most pronounced for women aged 70-85 years with a

Table I Characteristics of the study population

\begin{tabular}{|c|c|c|c|}
\hline Variable & Category & $n$ & Percent \\
\hline Age group & $\begin{array}{l}65-69 \\
70-74 \\
75-79 \\
80-84 \\
85+\end{array}$ & $\begin{array}{l}5769 \\
5650 \\
5205 \\
3566 \\
2848\end{array}$ & $\begin{array}{l}25.0 \\
24.5 \\
22.6 \\
15.5 \\
12.4\end{array}$ \\
\hline Co-morbidity & $\begin{array}{l}0 \\
1 \\
2+\end{array}$ & $\begin{array}{r}19749 \\
2310 \\
979\end{array}$ & $\begin{array}{r}85.7 \\
10.0 \\
4.3\end{array}$ \\
\hline Stage & $\begin{array}{l}\text { I } \\
\text { II } \\
\text { III } \\
\text { IV } \\
\text { Missing }\end{array}$ & $\begin{array}{l}6036 \\
9035 \\
1974 \\
1415 \\
4578\end{array}$ & $\begin{array}{r}26.2 \\
39.2 \\
8.6 \\
6.1 \\
19.9\end{array}$ \\
\hline Grade & $\begin{array}{l}1 \\
2 \\
3 \\
\text { Missing }\end{array}$ & $\begin{array}{l}3492 \\
9125 \\
5464 \\
4957\end{array}$ & $\begin{array}{l}15.2 \\
39.6 \\
23.7 \\
21.5\end{array}$ \\
\hline Deprivation & $\begin{array}{l}\text { I (Affluent) } \\
2 \\
3 \\
4 \\
5 \text { (Deprived) } \\
\text { Missing }\end{array}$ & $\begin{array}{r}3309 \\
4528 \\
4643 \\
4974 \\
5556 \\
28\end{array}$ & $\begin{array}{r}14.4 \\
19.7 \\
20.1 \\
21.6 \\
24.1 \\
0.1\end{array}$ \\
\hline Ethnicity & $\begin{array}{l}\text { White } \\
\text { Non-white } \\
\text { Missing }\end{array}$ & $\begin{array}{r}19043 \\
275 \\
3720\end{array}$ & $\begin{array}{r}82.7 \\
1.2 \\
16.1\end{array}$ \\
\hline Region & $\begin{array}{l}1 \\
2\end{array}$ & $\begin{array}{l}12669 \\
10369\end{array}$ & $\begin{array}{l}55.0 \\
45.0\end{array}$ \\
\hline Diagnosis period & $\begin{array}{l}1997-99 \\
2000-02 \\
2003-05\end{array}$ & $\begin{array}{l}7377 \\
8685 \\
6976\end{array}$ & $\begin{array}{l}32.0 \\
37.7 \\
30.3\end{array}$ \\
\hline Total & & 23038 & 100 \\
\hline
\end{tabular}

Surgery for older women with breast cancer and co-morbidity $\mathrm{K}$ Lavelle et al

co-morbidity score of $2+$. Women with metastatic (stage IV) or unknown stage of breast cancer were much less likely to have surgery than those with earlier-stage disease. Just under $90 \%$ of women with early-stage breast cancer in the whole sample had surgery compared to only $16.6 \%$ of those with stage IV and $36.5 \%$

Table 2 Number and proportion of women having primary surgery

\begin{tabular}{|c|c|c|c|}
\hline Variable & Category & No. of surgery & $\%$ Surgery \\
\hline Age group* & $\begin{array}{l}65-69 \\
70-74 \\
75-79 \\
80-84 \\
85+\end{array}$ & $\begin{array}{r}4983 \\
4564 \\
3826 \\
2161 \\
970\end{array}$ & $\begin{array}{l}86.4 \\
80.8 \\
73.5 \\
60.6 \\
34.1\end{array}$ \\
\hline Co-morbidity* & $\begin{array}{l}0 \\
1 \\
2+\end{array}$ & $\begin{array}{r}\mid 4494 \\
1529 \\
48 \mid\end{array}$ & $\begin{array}{l}73.4 \\
66.2 \\
49.1\end{array}$ \\
\hline Stage* & $\begin{array}{l}\text { I } \\
\text { II } \\
\text { II } \\
\text { IV } \\
\text { Missing }\end{array}$ & $\begin{array}{r}535 \mid \\
7896 \\
1352 \\
235 \\
1670\end{array}$ & $\begin{array}{l}88.7 \\
87.4 \\
68.5 \\
16.6 \\
36.5\end{array}$ \\
\hline Grade* & $\begin{array}{l}1 \\
2 \\
3 \\
\text { Missing }\end{array}$ & $\begin{array}{l}2955 \\
7619 \\
4653 \\
1277\end{array}$ & $\begin{array}{l}84.6 \\
83.5 \\
85.2 \\
25.8\end{array}$ \\
\hline Deprivation* & $\begin{array}{l}\text { I (Affluent) } \\
2 \\
3 \\
4 \\
5 \text { (Deprived) }\end{array}$ & $\begin{array}{l}2492 \\
3422 \\
3302 \\
3510 \\
3762\end{array}$ & $\begin{array}{l}75.3 \\
75.6 \\
71.1 \\
70.6 \\
67.7\end{array}$ \\
\hline Ethnicity ${ }^{\dagger}$ & $\begin{array}{l}\text { White } \\
\text { Non-white } \\
\text { Missing }\end{array}$ & $\begin{array}{r}13826 \\
213 \\
2465\end{array}$ & $\begin{array}{l}72.6 \\
77.5 \\
66.3\end{array}$ \\
\hline Region ${ }^{\dagger}$ & $\begin{array}{l}1 \\
2\end{array}$ & $\begin{array}{l}8910 \\
7594\end{array}$ & $\begin{array}{l}70.3 \\
73.2\end{array}$ \\
\hline Diagnosis period* & $\begin{array}{l}1997-09 \\
2000-02 \\
2003-05\end{array}$ & $\begin{array}{l}4970 \\
6298 \\
5236\end{array}$ & $\begin{array}{l}67.4 \\
72.5 \\
75.1\end{array}$ \\
\hline Total & & 16504 & 71.6 \\
\hline
\end{tabular}

All variables highly associated with receipt of surgery, that is, $* P$ (trend) $<0.001$; ${ }^{\dagger} P$ (Person) $<0.001$.

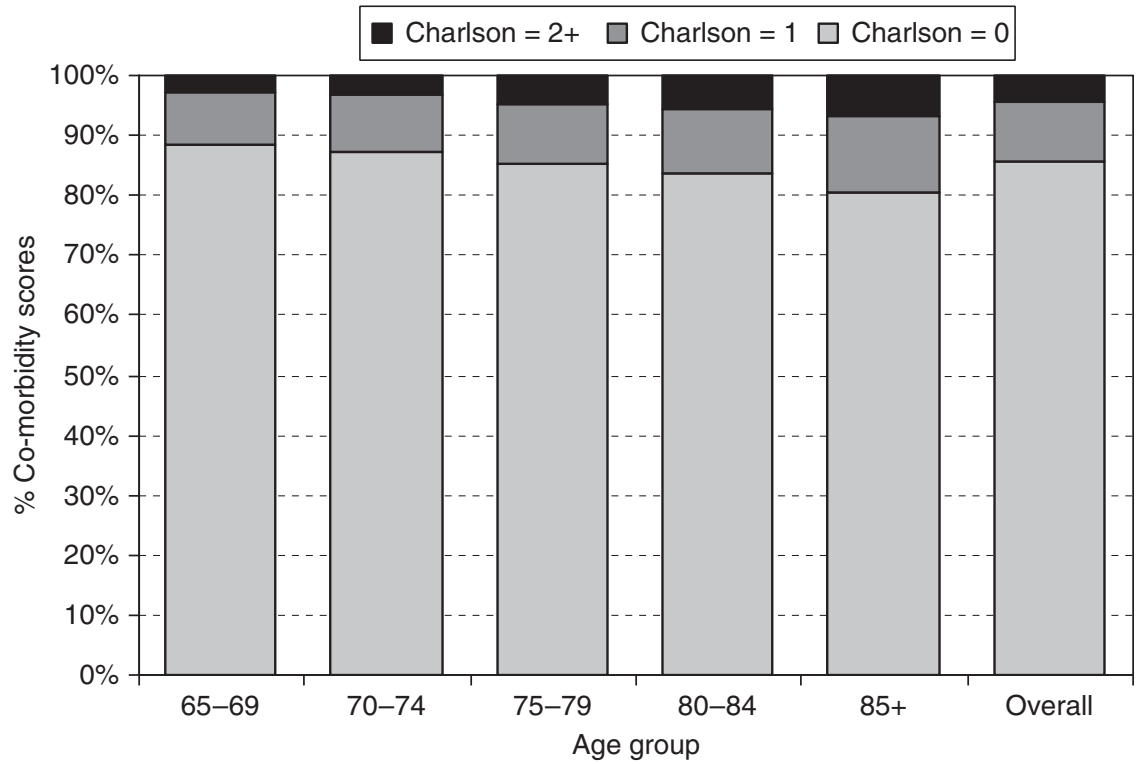

Figure I Chrison co-morbidity scores by age group. 


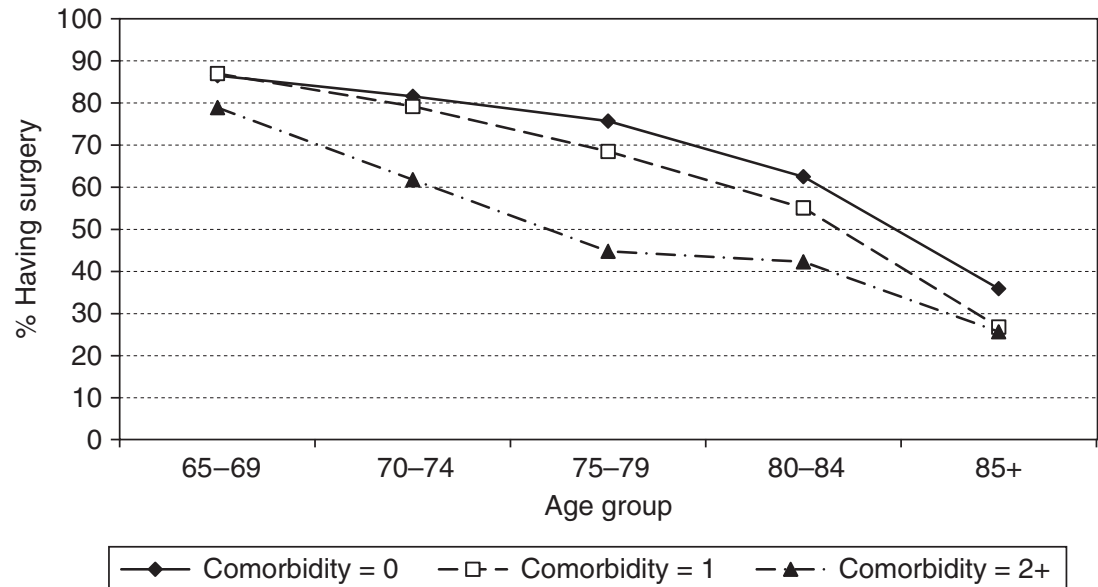

Figure 2 The proportion of patients having surgery by age group stratified by Charlson co-morbidity score.

of those with missing stage. There was little difference in the proportion of women receiving surgery by disease grade 1,2 or 3 (well, moderately or poorly differentiated; $84.6 \%, 83.5 \%$ and $85.2 \%$, respectively), but only $25.8 \%$ of those with missing information on grade had surgery. Treatment was also socially patterned. The proportion of women undergoing surgery was $75.3 \%$ in the most affluent quintile and this decreased to $67.7 \%$ in the most deprived quintile. There was some suggestion that nonWhite women were more likely to have surgery $(77.5 \%)$ than White women $(72.6 \%)$ but the numbers in the non-White category were very small. Women living in region 1 were slightly less likely to have surgery than women living in region 2 (70.3\% compared to $73.2 \%)$. The proportion of women who had surgery increased with each successive diagnosis period, from $67.4 \%$ in $1997-99$ to $75.1 \%$ in 2003-05.

The results of univariable and multivariable logistic regression models are shown in Table 3. In univariable analysis, the odds of receiving surgery diminished substantially with increasing age, with women aged $\geqslant 85$ years having 0.08 (95\% CI: $0.07-0.09)$ the odds of surgery compared with women aged 65-69 years. After controlling for the effect of co-morbidity (as well as other explanatory variables), age remained strongly predictive of surgery with the odds of receipt significantly lower for all age groups $\geqslant 70$ years compared with 65-69-year olds. Women with any comorbidity had significantly lower odds of receiving surgery compared with those with no co-morbidity (adjusted OR 0.75, 95\% CI: $0.67-0.84$ for those with a score of 1 ; adjusted OR 0.40 , 95\% CI: $0.34-0.48$ for those with a score of $2+$ ). Women with later stage and unknown stage breast cancer had reduced odds of surgery compared with those with stage 1 (adjusted OR 0.34, 95\% CI: $0.30-0.39$ for stage III; adjusted OR 0.02 , $95 \%$ CI: $0.02-0.03$ for stage IV; adjusted OR $0.10,95 \%$ CI: $0.09-0.11$ for missing stage). Region had an effect on receipt of surgery, women treated in region 2 had 1.70 times the odds of having surgery compared with women treated in region 1 (95\% CI: $1.58-1.84)$. Surgical rates increased over time with women diagnosed in the more recent time periods being more likely to receive surgery (adjusted OR 1.17, 95\% CI: $1.08-1.28$ for $2000-02$; adjusted OR 1.29 , 95\% CI: $1.17-1.41$ for 2003-05) compared with women diagnosed in 1997-99. Associations between age, surgery and co-morbidity were unaltered in analyses restricted to both early-stage disease and women aged under 85 years (data available online Tables S1 and S2).

\section{DISCUSSION}

To our knowledge, this is the first large-scale population-based study of treatment patterns for older women with breast cancer in
Table 3 Multivariable logistic regression of receiving primary surgery (vs not receiving primary surgery)

\begin{tabular}{|c|c|c|c|c|c|}
\hline Variable $^{a}$ & Category & $\begin{array}{l}\text { Unadjusted } \\
\text { odds ratio }\end{array}$ & $95 \% \mathrm{Cl}$ & $\begin{array}{c}\text { Adjusted } \\
\text { odds ratio }\end{array}$ & $95 \% \mathrm{Cl}$ \\
\hline Age group & $\begin{array}{l}65-69 \\
70-74 \\
75-79 \\
80-84 \\
85+\end{array}$ & $\begin{array}{l}\text { (Ref) } \\
0.66 \\
0.44 \\
0.24 \\
0.08\end{array}$ & $\begin{array}{c}- \\
0.60-0.73 \\
0.40-0.48 \\
0.22-0.27 \\
0.07-0.09\end{array}$ & $\begin{array}{l}\text { (Ref) } \\
0.74 \\
0.56 \\
0.32 \\
0.13\end{array}$ & $\begin{array}{c}- \\
0.66-0.83 \\
0.50-0.63 \\
0.28-0.36 \\
0.11-0.14\end{array}$ \\
\hline Co-morbidity & $\begin{array}{l}0 \\
1 \\
2+\end{array}$ & $\begin{array}{l}\text { (Ref) } \\
0.71 \\
0.35\end{array}$ & $\begin{array}{c}- \\
0.65-0.78 \\
0.31-0.40\end{array}$ & $\begin{array}{l}\text { (Ref) } \\
0.75 \\
0.40\end{array}$ & $\begin{array}{c}- \\
0.67-0.84 \\
0.34-0.48\end{array}$ \\
\hline Stage & $\begin{array}{l}\text { I } \\
\text { II } \\
\text { III } \\
\text { IV } \\
\text { Missing }\end{array}$ & $\begin{array}{l}\text { (Ref) } \\
0.89 \\
0.28 \\
0.03 \\
0.07\end{array}$ & $\begin{array}{c}- \\
0.80-0.98 \\
0.25-0.32 \\
0.02-0.03 \\
0.07-0.08\end{array}$ & $\begin{array}{l}\text { (Ref) } \\
1.01 \\
0.34 \\
0.02 \\
0.10\end{array}$ & $\begin{array}{c}- \\
0.91-1.13 \\
0.30-0.39 \\
0.02-0.03 \\
0.09-0.11\end{array}$ \\
\hline Region & $\begin{array}{l}1 \\
2\end{array}$ & $\begin{array}{c}\text { (Ref) } \\
1.15\end{array}$ & $1.09-1.22$ & $\begin{array}{c}\text { (Ref) } \\
1.70\end{array}$ & $1.58-1.84$ \\
\hline Diagnosis period & $\begin{array}{l}1997-99 \\
2000-02 \\
2003-05\end{array}$ & $\begin{array}{l}\text { (Ref) } \\
1.28 \\
1.46\end{array}$ & $\begin{array}{c}- \\
1.19-1.37 \\
1.35-1.57\end{array}$ & $\begin{array}{l}\text { (Ref) } \\
1.17 \\
1.29\end{array}$ & $\begin{array}{c}- \\
1.08-1.28 \\
1.17-1.4 \mid\end{array}$ \\
\hline
\end{tabular}

Abbreviation: $\mathrm{Cl}=$ confidence interval. ${ }^{2}$ Deprivation, not included as no significance effect in initial multivariable model. Grade and ethnicity not included as effect in initial

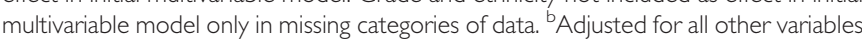
in the table.

the UK to incorporate a measure of co-morbidity. We confirmed that increasing age predicted lack of primary surgery for all age groups $\geqslant 70$, compared with 65-69-year olds. This disparity in treatment by age was evident in the whole sample, across both constituent regions and persisted when co-morbidity was adjusted for. This finding is in broad agreement with studies from the North America (Hillner et al, 1996; Giordano et al, 2005; Naeim et al, 2006) and the UK (Lavelle et al, 2007a).

Co-morbidity explained some of the variation observed in treatment. Although co-morbidity has been found to predict under-treatment in several previous studies of older women with breast cancer (Ballard-Barbash et al, 1996; Hérbert-Croteau et al, 1999; Giordano et al, 2005; Naeim et al, 2006), this is by no means a universal finding (Hillner et al, 1996; Silliman et al, 1997; Mandelblatt et al, 2000; Lavelle et al, 2007a). However, even after accounting for co-morbidity all of these studies still found older women were less likely to receive some aspect of standard treatment.

The two registries included in the study are broadly representative in terms of population structure and level of deprivation; covering approximately $23 \%$ of the population of England and 
35 of the 168 Acute NHS Hospital Trusts in the country. They have high-quality data, meeting all UKACR performance targets on completeness of breast cancer staging and treatment data (United Kingdom Association of Cancer Registries, 2011).

The routine measure of co-morbidity used in this study has informed, and been developed in the light of, national-level discussions (National Cancer Intelligence Network, 2010). This study represents an important step forward in building on these discussions to develop a routine measure of co-morbidity. The observed Charlson scores followed the anticipated patterns with patient age and social position. In line with other studies, estimated co-morbidity scores increased over time, probably due to increased recording of additional 'secondary diagnoses' within HES in more recent years (Trotter et al, 2008). The measure used here exhibits a strong association with receipt of surgery and accounts for some of the variation in surgery by age group. Although the use of routine data does not confer the same level of control over data collection as prospective, individual-level studies, the method used here enabled investigation of treatment patterns on a large scale from which a routine measure of comorbidity could be investigated. This provides a basis for further work to refine this routine measure and thereby provide the basis for a more level playing field for population/institutional comparisons of treatment access and outcomes.

A large sample size was achieved by using administrative data to score co-morbidity rather than reviewing individual medical records, but this approach has limitations. Administrative records drawn from secondary care underestimate cancer patient's total co-morbidity as they are based only on in-patient hospital admissions. Underestimation of co-morbidity is apparent in the lower proportion of older breast cancer patients having a Charlson score of $\geqslant 1$ in this study (14\%) when compared with the previous studies measuring co-morbidity from individual case note reviews (varies from 17-35\%) (Ballard-Barbash et al, 1996; Hérbert-Croteau et al, 1999; Hurria et al, 2003; Lavelle et al, 2007a).

Measurement of co-morbidity in this study was also dependent on linkage between data sets and there was evidence that this decreased with older age; the sample used in this study will underrepresent the oldest patients. The increase in proportion of cases registered via DCO with older age is likely to have contributed to the reduction in linkage as the HES data set currently available to the registries (and hence this study) is restricted to patients with a recorded diagnosis of cancer at some point. However, among those under 85 years old, where linkage rates are reasonably high, the pattern of access to surgery decreasing with older age, accounting for co-morbidity, is clearly demonstrated. There is evidence that the degree of linkage achievable in the oldest patients has improved in recent years, the National Cancer Data Repository containing merged data from cancer registries and HES shows an increase in linkage for breast cancer patients aged $\geqslant 85$ years old, from $44.3 \%$ in 1997 to $68.7 \%$ in 2007 (National Cancer Information Network, 2010; Northern and Yorkshire Cancer Registry and Information Service, 2011).

We found some differences between the two regions. National audit data for the UK suggest considerable variation in standard management between provider units, with the proportion of breast cancer patients aged $\geqslant 70$ years not receiving surgery varying between regions from 12 to 40\% (Breast Cancer Clinical Outcome Measures Project, 2007) and between hospitals from 8 to $77 \%$ (Monypenny, 2004). Although the authors acknowledge that it is possible that this reflects a true difference in clinical practice, they conclude that this variation is more likely to be due to underreporting to cancer registries of cases that were not surgically treated.

Treatment guidelines recommend surgery as the primary treatment for early-stage breast cancer. However, stage at diagnosis as recorded in cancer registries has been largely based on surgical specimens. Restricting the sample to early-stage breast cancer would have conditioned our analyses on the basis of the primary outcome, that is, selectively excluding women not undergoing surgery. However, when analyses were limited to patients with stage I and II disease identical patterns were seen, with less surgery observed in older women and only limited attenuation of this affect when adjusted for co-morbidity.

The results of this study suggest that for women aged $\geqslant 65$ years the chance of surgery increased with time over the 9 years of the study. Although this may in part reflect improving completeness of treatment data, increasing surgical rates over time have also been reported in national audits (National Clinical Audit Support Programme, 2009). It therefore seems likely that the improved surgical rates also demonstrate changes in practice, reflecting the guidelines that were published and the major reorganising of cancer services over the period of time covered by this study (1997-2005) (Clinical Oncology Information Network (COIN), 1999; British Association of Surgical Oncologists (BASO), 1998; Scottish Intercollegiate Guidelines Network, 2005; Department of Health, 2000).

The Cancer Reform Strategy states that the only acceptable reasons for cancer patients not receiving clinically appropriate treatment are poor patient health and choice (Department of Health, 2007). However, in order to truly measure suboptimal treatment, the potential confounding effects of these factors need to be adjusted for. In this study, we adjusted for co-morbidity, but wider measures of health such as functional health/ performance status (or frailty) have also been found to predict under-treatment of older breast cancer patients (Lavelle et al, 2007a) independently from co-morbidity (Extermann et al, 1998). In our study, the largest difference in surgical rates by co-morbidity occurs for women aged 79-84 years, perhaps indicating a greater influence from wider measures of health for patients aged over 85 years. Two cohort studies in the USA have attempted to measure and account for patient choice in clinical decisions for older women with breast cancer. Although both found that patient's preferences were associated with treatment, increasing age remained strongly predictive of under-treatment in models accounting for patient choice (Silliman et al, 1997; Mandelblatt et al, 2000). Further prospective, cohort studies are currently being undertaken in the UK to investigate the extent to which patients choice and poor health explains the difference is treatment between older and younger women in this country (UK Clinical Research Network Portfolio Database, 2011a, b).

The results of this study indicate that although co-morbidity is associated with a reduced likelihood of surgery, it does not explain the shortfall in surgery among older women in the UK. However, investigation of age-bias in access to treatment requires further research on two fronts. Routine measures of co-morbidity need further development to ensure completeness and thereby a means of fairer comparison of access to surgery between demographic groups on a national level. In addition, prospective cohort studies are needed to examine the extent to which co-morbidity and wider measures of health (such as frailty) as well as patient choice explain the lack of surgery for older breast cancer patients.

\section{ACKNOWLEDGEMENTS}

This study was funded by Cancer Research UK (A8256) and independent research arising from a Post Doctoral Fellowship supported by the National Institute for Health Research (PDF/01/ 2008/027). The views expressed in this publication are those of the author(s) and not necessarily those of the NHS, the National Institute for Health Research or the Department of Health.

Supplementary Information accompanies the paper on British Journal of Cancer website (http://www.nature.com/bjc) 


\section{REFERENCES}

Ali AMG, Greenberg D, Wishart GC, Pharoah P (2011) Patient and tumour characteristics, management, and age-specific survival in women with breast cancer in the East of England. Br J Cancer 104: 564-570

Association of Breast Surgery at BASO (2009) Surgical guidelines for the management of breast cancer. Eur J Surg Oncol 35(Suppl 1): 1-22

Balducci L, Extermann M, Carreca I (2001) Management of breast cancer in the older woman. Cancer Control 8: 431-441

Ballard-Barbash R, Potsky AL, Harlan LC, Nayfield SG, Kessler LG (1996) Factors associated with surgical and radiation therapy for early stage breast cancer in older women. J Natl Cancer Inst 88: 716-726

Bloom HJ, Richardson WW (1957) Histological grading and prognosis in breast cancer; a study of 1409 cases of which 359 have been followed for 15 years. Br J Cancer 11(3): 359-377

Bouchardy C, Rapiti E, Blagojevic S, Vlastos AT, Vlastos G (2007) Older female cancer patients: importance, causes, and consequences of undertreatment. [Review] [139 refs]. J Clin Oncol 25: 1858-1869

Breast Cancer Clinical Outcome Measures Project (2007) Analysis of the management of symptomatic breast cancers diagnosed in 2004, $3^{\text {rd }}$ Year Report. West Midlands Cancer Intelligence Unit: Birmingham

British Association of Surgical Oncologists (BASO) (1998) Guidelines for Surgeons in the Management of Symptomatic Breast Disease in the United Kingdom. Breast Speciality Group: London

Cancer Research UK. Breast Cancer Survival Statistics. http://info. cancerresearchuk.org/cancerstats/types/breast/survival/\#age. 2009.

Charlson M, Pompei P, Ales K, MacKenzie C (1987) A new method of classifying prognostic co-morbidity in longitudinal studies: development and validation. J Chronic Dis 40: 373-383

Clinical Oncology Information Network (COIN) (1999) Guidelines on the Non-surgical Management of Breast Cancer: A Document for Local Expert Groups in the United Kingdom Preparing Breast Management Policy Documents. The Royal College of Radiologists: London

Coleman MP, Forman D, Bryant H, Butler J, Rachet B, Maringe C, Nur U, Tracey E, Coory M, Hatcher J, McGahan CE, Turner D, Marrett L, Gjerstorff ML, Johannesen TB, Adolfsson J, Lambe M, Lawrence G, Meechan D, Morris EJ, Middleton R, Steward J, Richards MA, Module ICBP (2011) Cancer survival in Australia, Canada, Denmark, Norway, Sweden, and the UK, 1995-2007 (the International Cancer Benchmarking Partnership): an analysis of population-based cancer registry data. Lancet 377(9760): 127-138

Coleman MP, Quaresma M, Berrino F, Lutz JM, De AR, Capocaccia R, Baili P, Rachet B, Gatta G, Hakulinen T, Micheli A, Sant M, Weir HK, Elwood JM, Tsukuma H, Koifman S, Francisci S, Santaquilani M, Verdecchia A, Storm HH, Young JL, CONCORD Working Group (2008) Cancer survival in five continents: a worldwide population-based study (CONCORD). Lancet Oncol 9(8): 730-756

Department of Health (2007) Cancer Reform Strategy. DOH: London

Department of Health The NHS Cancer Plan: A Plan for Investment, a Plan for Reform (2000) DOH: London

Extermann M, Overcash J, Lyman G, Parr J, Balducci L (1998) Co-morbidity and functional status are independent in older cancer patients. J Clin Oncol 16: 1582-1587

Foot C, Harrison T (2011) How to improve cancer survival: Explaining England's relatively poor rates. The King's Fund: London

Giordano SH, Hortobagyi GN, Kau S-WC, Theriault RL, Bondy ML (2005) Breast cancer treatment guidelines in older women. J Clin Oncol 23: 783-791

Health and Social Care Information Centre. Hospital Episode Statistics Online. www.hesonline.nhs.uk. 2009

Hérbert-Croteau N, Brisson J, Latreille J, Blanchette C, Deschênes L (1999) Compliance with consensus recommendations for the treatment of early stage breast carcinoma in elderly women. Cancer 85: 1104-1113

Hillner BE, Penberthy L, Desch CE, McDonald MK, Smith TJ, Retchin SM (1996) Variation in staging and treatment of local and regional breast cancer in the elderly. Breast Cancer Res Treat 40: 75-86

Hind D, Wyld L, Reed MW (2007) Surgery, with or without tamoxifen, vs tamoxifen alone for older women with operable breast cancer: Cochrane review. Br J Cancer 96: 1025-1029

Hurria A, Leung D, Trainor K, Borgen P, Norton L, Hudis C (2003) Factors influencing treatment patterns of breast cancer patients age 75 and older. [Review] [87 refs]. Crit Rev Oncol Hematol 46(2): 121-126

Imamura K, McKinnon M, Middleton R, Black N (1997) Reliability of a comorbidity measure: the Index of Co-Existent Disease (ICED). J Clin Epidemiol 50(9): 1011-1016
Lavelle K, Moran A, Howell A, Bundred N, Campbell M, Todd C (2007a) Older women with operable breast cancer are less likely to have surgery. Br J Surg 94: 1209-1215

Lavelle K, Todd C, Moran A, Howell A, Bundred N, Campbell M (2007b) Non-standard management of breast cancer increases with age in the UK: a population based cohort of women $>$ or $=65$ years. Br J Cancer 96: 1197-1203

Lawrence G, Kearins O, Lagord C, Cheung S, Sidhu J, Sagar C (2011) The Second All Breast Cancer Report. National Cancer Intelligence Network: London

Louwman WJ, Vulto JC, Verhoeven RH, Nieuwenhuijzen GA, Coebergh JW, Voogd AC (2007) Clinical epidemiology of breast cancer in the elderly. [Review] [44 refs]. Eur J Cancer 43: 2242-2252

Mandelblatt JS, Hadley J, Kerner JF, Schulman KA, Gold K, DunmoreGriffith J, Edge S, Guadagnoli E, Lynch JJ, Meropol NJ, Weeks JC, Winn R (2000) Patterns of breast carcinoma treatment in older women: patient preference and clinical and physician influences. Cancer 89: 561-573

Monypenny I. UK Symptomatic Breast Audit 1/4/2002 - 31/3/2003 (2004) British Association of Surgical Oncologists: London

Naeim A, Hurria A, Leake B, Maly RC (2006) Do age and ethnicity predict breast cancer treatment received? A cross-sectional urban population based study. Breast cancer treatment: age and ethnicity. Crit Rev Oncol Hematol 59: 234-242

National Cancer Information Network. National Cancer Data Repository. http://www.ncin.org.uk/collecting_and_using_data/national_cancer_data_ repository/default.aspx. 2010.

National Cancer Intelligence Network (2010) Comorbidity data collection. www.ncin.org.uk/collecting_and_using_data/data_collection/comorbidity. aspx.

National Clinical Audit Support Programme (2009) National mastectomy and breast reconstruction audit. http://www.ic.nhs.uk/webfiles/Services/ NCASP/Cancer/new\%20web\%20documents\%20(MBR)/NHS_IC\%20MBR_ CLINICAL_AUDIT_2009.pdf.

National Institute for Clinical Excellence Early and Locally Advanced Breast Cancer: Diagnosis and Treatment (2009) NICE: London

Northern and Yorkshire Cancer Registry and Information Service (2011) Increase in linkage for older breast cancer patients from 1997-2007. Personal communication to K Lavelle 14 November 2011.

Office for National Statistics (2010) Cancer statistics registrations: Registrations of cancer diagnosed in 2008, England. Series MB1 No. 39. www.statistics.gov.uk.

Office of the Deputy Prime Minister The English Indices of Deprivation 2004 Summary (revised) (2005) Office of the Deputy Prime Minister: London

Ring A, Reed M, Leonard R, Kunkler I, Muss H, Wildiers H, Fallowfield L, Jones A, Coleman R (2011) The treatment of early breast cancer in women over the age of 70. Br J Cancer 105(2): 189-193

Scottish Intercollegiate Guidelines Network (2005) Management of Breast Cancer in Women: A National Clinical Guideline. Scottish Intercollegiate Guidelines Network: Edinburgh

Silliman RA, Troyan S, Guadagnoli E, Kaplan S, Greenfield S (1997) The impact of age, marital status and physician-patient interaction on the care of older women with breast carcinoma. Cancer 80: 1326-1334

Trotter CL, Stuart JM, George R, Miller E (2008) Increasing hospital admissions for pneumonia, England. Emerg Infect Dis 14(5): 727-733

UICC (2002) TNM Classification of Malignant Tumours. 6th Edition. International Union Against Cancer. Wiley-Liss: New York

UK Clinical Research Network Portfolio Database (2011a) Management of breast cancer for women aged $65+$ in Northwest England UKCRN 8599. http://public.ukcrn.org.uk/Search/StudyDetail.aspx?StudyID=8599.

UK Clinical Research Network Portfolio Database (2011b) Management of breast cancer for women aged $70+$ in Greater Manchester UKCRN 8598. http://public.ukcrn.org.uk/Search/StudyDetail.aspx?StudyID=8598.

United Kingdom Association of Cancer Registries (2011) Quality and Performance Indicators. http://www.ukacr.org/content/data-quality.

Wyldes L, Garg D, Kumar I, Brown H, Reed M (2004) Stage and treatment variation with age in postmenopausal women with breast cancer: compliance with guidelines. Br J Cancer 90: 1486-1491

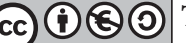

This work is licensed under the Creative Commons Attribution-NonCommercial-Share Alike 3.0 Unported License. To view a copy of this license, visit http:// creativecommons.org/licenses/by-nc-sa/3.0/ 